European Psychiatry

www.cambridge.org/epa

\section{Research Article}

Cite this article: Fiorillo A, Sampogna G, Giallonardo V, Del Vecchio V, Luciano M, Albert U, Carmassi C, Carrà G, Cirulli F, Dell'Osso B, Nanni MG, Pompili M, Sani G, Tortorella A, Volpe U (2020). Effects of the lockdown on the mental health of the general population during the COVID-19 pandemic in Italy: Results from the COMET collaborative network. European Psychiatry, 63(1), e87, 1-11 https://doi.org/10.1192/j.eurpsy.2020.89

Received: 07 September 2020

Revised: 22 September 2020

Accepted: 22 September 2020

Key words:

Anxiety; COVID-19; depression; lockdown; pandemic; stress

Author for correspondence:

${ }^{*}$ Andrea Fiorillo,

E-mail: andrea.fiorillo@unicampania.it

\title{
Effects of the lockdown on the mental health of the general population during the COVID-19 pandemic in Italy: Results from the COMET collaborative network
}

\author{
Andrea Fiorillo $^{1}$, Gaia Sampogna ${ }^{1}$, Vincenzo Giallonardo ${ }^{1}$ (D), Valeria Del Vecchio ${ }^{1}$, \\ Mario Luciano ${ }^{1}$, Umberto Albert $^{2}$, Claudia Carmassi ${ }^{3}$, Giuseppe Carrà ${ }^{4}$ (D), \\ Francesca Cirulli ${ }^{5}$ (D), Bernardo Dell'Osso ${ }^{6}$, Maria Giulia Nanni ${ }^{7}$, Maurizio Pompili ${ }^{8}$ (D), \\ Gabriele Sani $^{9,10}$, Alfonso Tortorella ${ }^{11}$ and Umberto Volpe ${ }^{12}$
}

${ }^{1}$ Department of Psychiatry, University of Campania “L. Vanvitelli", Naples, Italy; ${ }^{2}$ Department of Medicine, Surgery and Health Sciences, University of Trieste and Department of Mental Health, Azienda Sanitaria Universitaria Giuliano Isontina - ASUGI, Trieste, Italy; ${ }^{3}$ Department of Clinical and Experimental Medicine, University of Pisa, Pisa, Italy; ${ }^{4}$ Department of Medicine and Surgery, University of Milan Bicocca, Milan, Italy; ${ }^{5}$ Center for Behavioral Sciences and Mental Health, National Institute of Health, Rome, Italy; ${ }^{6}$ Department of Biomedical and Clinical Sciences Luigi Sacco and Aldo Ravelli Center for Neurotechnology and Brain Therapeutic, University of Milan, Milano, Italy; ${ }^{7}$ Institute of Psychiatry, Department of Biomedical and Specialty Surgical Sciences, University of Ferrara, Ferrara, Italy; ${ }^{8}$ Department of Neurosciences, Mental Health and Sensory Organs, Faculty of Medicine and Psychology, Sapienza University of Rome, Rome, Italy; ${ }^{9}$ Department of Neuroscience, Section of Psychiatry, University Cattolica del Sacro Cuore, Rome, Italy; ${ }^{10}$ Department of Psychiatry, Fondazione Policlinico Agostino Gemelli IRCCS, Rome, Italy; ${ }^{11}$ Department of Psychiatry, University of Perugia, Perugia, Italy and ${ }^{12}$ Clinical Psychiatry Unit, Department of Clinical Neurosciences, Università Politecnica delle Marche, Ancona, Italy

\begin{abstract}
Background. The Coronavirus disease 2019 (COVID-19) pandemic is an unprecedented traumatic event influencing the healthcare, economic, and social welfare systems worldwide. In order to slow the infection rates, lockdown has been implemented almost everywhere. Italy, one of the countries most severely affected, entered the "lockdown" on March 8, 2020.

Methods. The COvid Mental hEalth Trial (COMET) network includes 10 Italian university sites and the National Institute of Health. The whole study has three different phases. The first phase includes an online survey conducted between March and May 2020 in the Italian population. Recruitment took place through email invitation letters, social media, mailing lists of universities, national medical associations, and associations of stakeholders (e.g., associations of users/ carers). In order to evaluate the impact of lockdown on depressive, anxiety and stress symptoms, multivariate linear regression models were performed, weighted for the propensity score.

Results. The final sample consisted of 20,720 participants. Among them, $12.4 \%$ of respondents $(N=2,555)$ reported severe or extremely severe levels of depressive symptoms, $17.6 \%(N=3,627)$ of anxiety symptoms and $41.6 \%(N=8,619)$ reported to feel at least moderately stressed by the situation at the DASS-21.

According to the multivariate regression models, the depressive, anxiety and stress symptoms significantly worsened from the week April 9-15 to the week April 30 to May $4(p<0.0001)$. Moreover, female respondents and people with pre-existing mental health problems were at higher risk of developing severe depression and anxiety symptoms $(p<0.0001)$.

Conclusions. Although physical isolation and lockdown represent essential public health measures for containing the spread of the COVID-19 pandemic, they are a serious threat for mental health and well-being of the general population. As an integral part of COVID-19 response, mental health needs should be addressed.
\end{abstract}

(c) The Author(s), 2020. Published by Cambridge University Press on behalf of European Psychiatry. This is an Open Access article, distributed under the terms of the Creative Commons Attribution licence (http:// creativecommons.org/licenses/by/4.0/), which permits unrestricted re-use, distribution, and reproduction in any medium, provided the original work is properly cited.

EUROPEAN PSYCHIATRIC ASSOCIATION

\section{Background}

There is no doubt that the Coronavirus disease 2019 (COVID-19) pandemic, and its related containment measures such as lockdown, is affecting mental health of the general population worldwide [1-3]. This is an unprecedented event, which is influencing the healthcare, political, economic, and social systems [4]. Given the high level of contagiousness, as well as the lack of appropriate treatments and vaccines, almost all countries have adopted confinement measures, including lockdown, home isolation and physical distancing [5]. While most of the clinical and research efforts have been directed to reduce the effects of the virus on physical health [6-8], its short- and long-term effects on mental health are causing a second wave of pandemic, which has been mostly neglected [9-11]. Furthermore, the pandemic represents a traumatic event which 
has differential effects at individual and population levels. At the individual level, high rates of depression, anxiety, fear, panic, anger, and insomnia have been documented in studies mainly carried out in China or from short-term reports [12-14]. At the population level, the pandemic is associated with a range of psychosocial adversities, including economic hardship and financial losses (due to unemployment and reduced income), school closures, inadequate resources for medical response, domestic violence, and deficient distribution of basic good necessities [15]. The psychopathological consequences include the fear of contracting the disease and of dying, losing livelihoods and loved ones, uncertainty and worries about the future, social discrimination, and separation from families and caregivers [16-19]. This is why the current pandemic represents a new, complex and multifaceted form of psychosocial stressor [20], being completely different from other natural disasters [21], such as earthquakes or tsunamis [22, 23], wars, terroristic attacks, mass conflicts, or economic crisis [24-31], and also from previous epidemics, such as severe acute respiratory syndrome (SARS), Middle East respiratory syndrome (MERS) and Ebola $[32,33]$.

Italy has been the first western country heavily affected by the pandemic, and it has been the country with the highest number of infected and dead people for many weeks [34]. On March 8, 2020, the Italian Prime Minister has placed 60 million people under lockdown. This measure has been prolonged for 8 weeks, until May 3, 2020. This period is known as "Phase one," during which all not necessary activities have been closed, more than 29,000 people have died and almost 100,000 people have been homeisolated. During the initial phase of the pandemic, the outbreak in Italy seemed to have a greater severity of the disease, with a higher case fatality rate (CFR) than previously observed in China (7.2 vs. $2.3 \%$ ) [35]. The excess in COVID-19 mortality was higher in men than in women living in northern cities versus in central and southern Italy (men: $+87 \%$ and $+70 \%$ and women: $+17 \%$ and $+9 \%$, respectively), with an increasing trend by age [36].

From May 4, a gradual reopening of financial and commercial activities has taken place (known as "Phase two" of the national sanitary emergency). A few, short-term studies have already shown the impact of lockdown on the mental health of the Italian general population in the first days of "Phase one" [37-39]. We have decided to carry out an online survey using several validated assessment instruments in order to evaluate the impact of the lockdown on the mental health of Italian population throughout the different weeks of Phase one [40]. In particular, in this paper we aim to: (a) report the levels of depressive, anxiety and stress symptoms in a large sample of the Italian general population; (b) explore the levels of depressive, anxiety and stress symptoms during the different weeks of lockdown; and (c) identify possible risk and protective factors for mental health outcome.

\section{Methods}

\section{Study design}

The COvid Mental hEalth Trial (COMET) is a national trial coordinated by the University of Campania "Luigi Vanvitelli" (Naples) in collaboration with nine university sites: Università Politecnica delle Marche (Ancona), University of Ferrara, University of Milan Bicocca, University of Milan "Statale", University of Perugia, University of Pisa, Sapienza University of Rome, "Catholic" University of Rome, University of Trieste. The Center for Behavioral Sciences and Mental Health of the National Institute of Health in Rome has been involved in the study by supporting the dissemination and implementation of the project according to the clinical guidelines produced by the National Institute of Health for managing the effects of the COVID-19 pandemic.

The COMET trial includes three phases: phase one consists in the dissemination of a survey on the impact of lockdown and its related containment measures on the mental health of the Italian general population; the second phase consists in the development of a new psychosocial online supportive intervention [41-48] for the management of the consequences on mental health of the pandemic; the last phase consists in the evaluation of the efficacy and feasibility of the experimental psychosocial intervention in a randomized control trial. The results of phase 1 are described in this paper. The study has been approved by the Ethical Review Board of the coordinating center (protocol number: 0007593/i).

\section{Primary and secondary outcomes}

The primary outcome of the study is the severity of depressive-anxiety symptoms evaluated with the Depression, Anxiety, Stress Scale (DASS-21) [49]. Secondary outcomes include the levels of global mental health status, of obsessive-compulsive and post-traumatic symptoms, presence and severity of insomnia, the levels of perceived loneliness and the presence of suicidal ideation/suicidal thoughts. Furthermore, exploratory variables include coping strategies, levels of post-traumatic growth, perceived social support and resilience.

\section{Assessment tools}

The DASS-21 evaluates the general distress on a tripartite model of psychopathology [49] and is a reliable and valid measure in assessing mental health in the general population [50], which has been already adopted in previous research on SARS [51] and COVID-19 $[14,52]$. The DASS consists of 21 items grouped in three subscales: depression, anxiety, and stress. Each item is rated on a 4-level Likert scale, from 0 (never) to 3 (almost always). The total score is calculated by adding together the response values of each item, with higher scores indicating more severe levels of depressive, anxiety, and stress symptoms. The score at the DASS-depression subscale (e.g., "I felt that I had nothing to look forward to") is divided into normal (0-9), mild (10-12), moderate (13-20), severe (21-27), and extremely severe depression (28-42). The score at the DASS - anxiety subscale (e.g., "I was worried about situations in which I might panic and make a fool of myself") is divided into normal (0-6), mild (7-9), moderate (10-14), severe (15-19), and extremely severe anxiety (20-42). The score at the DASS-stress subscale (e.g., "I tended to over-react to situations") is divided into normal (0-10), mild (11-18), moderate (19-26), severe (27-34), and extremely severe stress (35-42).

The General Health Questionnaire (GHQ) - 12 items version explores participants' mental health status through six positively worded items (e.g., "Have you been able to concentrate"?) and six negatively worded items (e.g., "Have you lost much sleep over worry?"). The standard scoring method recommended by Goldberg for the need of case identification is called "GHQ method." Scores for the first two types of answers are " 0 " (positive) and for the other two are "1" (negative). Threshold $\geq 4$ at GHQ identifies people with a probability $>80 \%$ of having a mental health problem [53].

The Obsessive-Compulsive Inventory-Revised version (OCIR) consists of 18 items rated on a 5-level Likert scale, ranging from 0 to 4 . The total score is calculated by adding all single items. Scores above the threshold of 21 are indicative of an OCD diagnosis [54]. 
The Insomnia Severity Index (ISI) includes seven items rated on a 5 -level Likert scale (from 0 to 4 ), with a total score ranges from 0 to 28 [55].

The Suicidal Ideation Attributes Scale (SIDAS) consists of five items assessing frequency, controllability, closeness to attempt, level of distress associated with suicidal thoughts and impact on daily functioning. Each item is assessed on a 10-level Likert scale, with a total score ranging from 0 to 50 . In case of scoring " $0-$ Never" to the first item, all other items are skipped, and the total score is zero. The presence of any suicidal ideation is considered indicative of risk for suicidal behavior, while a cut-off of 21 is used to indicate high risk of suicidal behavior [56].

The Severity-of-Acute-Stress-Symptoms-Adult scale (SASS), which consists of nine items rated on a 5-point scale (from $0=$ Not at all to $4=$ Extremely), has been used to assess the presence of traumatic stress symptoms. The total score ranges from 0 to 28 , with higher scores indicating a greater severity of acute stress disorders [57].

The Impact of Event Scale (IES) - short version measures the traumatic reactions in people who have experienced traumatic events. Each item is rated on a 5-point scale ranging from 0 (not at all) to 5 (often). The IES evaluates the dimensions of intrusion, avoidance, and alteration in arousal [58].

The UCLA loneliness scale-short version is an eight-item scale designed to measure subjective feelings of loneliness, as well as feelings of social isolation. Each item is scored on a 4-level Likert scale from $0=$ never to $3=$ often [59].

The Brief-COPE consists of 28 items grouped in 14 subscales [60]. Each item is rated on a 4-level Likert scale from $0=$ "I have not been doing this at all" to 3 = "I have been doing this a lot." Coping strategies are divided in maladaptive strategies, including denial, venting, behavioral disengagement, self-blame, self-distraction and substance abuse, and adaptive coping strategies, which include emotional support, use of information, positive reframing, planning and acceptance. Two other subscales include religion and humour.

The short form of Post-Traumatic Growth Inventory (PTGI) is a 10-item assessment instrument grouped into five dimensions: relating to others, new possibilities, personal strengths, spiritual change, and appreciation of life. Items are rated on a 6-point Likert scale, from $0=$ "I did not experience this change as a result of my crisis" to $5=$ "I experienced this change to a very great degree as a result of my crisis". Higher scores indicate higher levels of post-traumatic growth [61].

The Connor-Davidson resilience scale (CD-RISC), which includes 10 items rated on a 6-level Likert scale, is subdivided into the following five factors: (a) personal competence, high standards, and tenacity; (b) trust in one's instincts, tolerance of negative affect, and strengthening effects of stress; (c) positive acceptance of change and secure relationships; (d) control; and (e) spiritual influences. Higher values indicate higher levels of resilience [62].

The Multidimensional Scale of Perceived Social Support (MSPPS) consists of 12 items rated on a 7 level-Likert scale, from $1=$ "absolutely false" to 7 = "absolutely true". Items are grouped into three dimensions: family support, support by friends and support by significant others. Higher values correspond to higher levels of perceived support [63].

The Maslach Burnout Inventory (MBI) has been used to evaluate the levels of burn-out in medical personnel [64]. Data regarding healthcare professionals are not included in this paper since they are out of the aims of the study and will be reported in subsequent analyses.
Respondents' socio-demographic (e.g., gender, age, geographical region, working and housing condition, etc.) and clinical information (e.g., having a previous physical or mental disorder, using illicit drugs or medications, etc.) have been collected through an ad-hoc schedule.

\section{Methodology}

The phase one of the COMET trial consists in an online survey carried out between March and May 2020 in the Italian adult population. The survey has been implemented through a multistep procedure: (a) email invitation to healthcare professionals and their patients; (b) social media channels (Facebook, Twitter, Instagram); (c) mailing lists of universities, national medical associations and associations of stakeholders (e.g., associations of users/carers); and (d) other official websites (e.g., healthcare or welfare authorities websites).

The online survey has been set up through EUSurvey, a web platform promoted by the European Commission (2013). The survey has been officially launched on March 30, 2020, and it takes approximately $30 \mathrm{~min}$ (range $15-45 \mathrm{~min}$ ) to be completed.

The full study protocol is available elsewhere [40].

\section{Statistical analysis}

Descriptive statistics were performed in order to describe the sociodemographic and clinical characteristics of the sample. The time points of data collection were recorded and coded using the variable "Week" (categorical: Week 1-March 30/April 8 (reference category); Week 2-April 9/April 15; Week 3-April 16/April 22; Week 4-April 23/April 29; Week 5-April 30/May 4). According to the official data of the Italian Ministry of Health, Lombardy, Piedmont, Veneto and Emilia-Romagna were the regions with the highest rate of new COVID cases and of COVID-related mortality (http://www. salute.gov.it/portale/nuovocoronavirus). Therefore, geographical regions of respondents were recoded using a binary variable "Severely impacted area." This variable has been entered in the regression model in order to evaluate the direct impact of living in an area with a higher risk of being infected rather than the impact of geographical area per se. We hypothesized that individuals living in the most affected areas should have presented more severe symptoms compared with those living in less affected areas.

By order of the Italian health authority, persons subject to quarantine are forbidden to move from home or residence for 14 days, with the aim to separate persons exposed (or potentially exposed) to the infectious agent from the general community for reducing the contagion rate. People who have been subjected to those restrictions were coded using the binary variable "Quarantine."

In order to adjust for the likelihood of participants of being exposed to COVID infection in each week, a propensity score was calculated [65]. This methodological choice was due to the fact that the propensity score produces a better adjustment for differences at baseline, rather than simply including potential confounders in the multivariable models. The propensity score was calculated using as independent variables age, gender, socioeconomic status and living in a severely impacted area [66]. In the final regression model, the inverse probability weights, based on the propensity score, were applied in order to model for the independence between exposure to the infection, outcomes and estimation of causal effects.

In order to evaluate factors associated with the severity of depressive, anxiety and stress symptoms at DASS-21 (primary outcomes), multivariate linear regression models were performed, 
including as independent variables: being infected by COVID-19, having a pre-existing mental disorder, being a healthcare professional. Furthermore, in order to evaluate the impact of the duration of lockdown and of other related containment measures on the primary outcomes, the categorical variable "Week" was also entered in the regression models. The models were adjusted for the rate of new COVID cases and of COVID-related mortality during the study period, as well as for several socio-demographic characteristics, such as gender, age, occupational status, having a physical comorbid condition, hours spent on Internet, levels of perceived loneliness, health status, number of cohabiting people, level of satisfaction with one's own life, with cohabiting people, with the housing condition. Missing data have been handled using the multiple imputation approach [67].

Statistical analyses were performed using the Statistical Package for Social Sciences (SPSS), version 17.0 and STATA, version 15. For all analyses, the level of statistical significance was set at $p<0.05$.

\section{Results}

\section{Sociodemographic characteristics}

The final sample consisted of 20,720 participants, $71 \%$ female $(N=$ $14,720)$, with a mean age of 40.4 (14.3) years; half of respondents were in a stable relationship, living with the partner $(52.2 \%, N=$ $10,808)$ (Table 1$)$. The vast majority of participants were employed $(70.1 \%, N=14,518)$ and $34.2 \%(N=7,089)$ shifted to smart working during the pandemic. $(N=1,302)$ of respondents lost their job during the pandemic. $80 \%$ spent more time on Internet than usual, more frequently for instant messaging $(85.3 \%, N=17,683)$, searching for information $(81.6 \%, N=16,899)$, or using social networks $(62.1 \%, N=12,867)$. About $14.5 \%$ of cases $(N=3,012)$ suffered from a pre-existing physical illness, mainly cardiovascular diseases (24.7\%), osteo-articular disorders (17.5\%), thyroid dysfunctions (9\%), and diabetes/dyslipidaemia (7.6\%). 5.5\% $(N=1,133)$ reported to have a pre-existing mental disorder, more frequently anxiety (34.3\%) and depressive disorders (35.5\%). $14 \%$ of respondents $(N=$ $2,907)$ were healthcare professionals.

\section{Clinical characteristics}

Almost all participants (91.2\%, $N=18,882)$ scored above the threshold of 4 at the GHQ, indicating the risk of having any mental health problem. In particular, depressive symptoms were moderate in $36.5 \%$ of respondents $(N=10,124)$ and severe or extremely severe in $12.4 \%(\mathrm{~N}=2,555)$; anxiety symptoms were moderate in $16.7 \%(N=3,469)$ of respondents and severe or extremely severe in $17.6 \%(N=3,633)$; stress symptoms were at least moderate in $41.6 \%$ $(N=8,619)$ (Table 2).

Moderate to severe levels of insomnia were found in $38.8 \%$ of respondents $(N=8,031)$. About $11.3 \%(N=2,332)$ of the sample scored above the threshold for clinical relevance of obsessivecompulsive symptomatology, with a global severity of obsessivecompulsive symptoms of $10.7( \pm 8.2)$ at OCI-R. Suicidal ideation is reported by $14.2 \%(N=2,976)$ of the sample, with a mean score of 4.9 (6.6) at the SIDAS.

Participants showed high levels of avoidance and hyperarousal symptoms ( $2.3 \pm 2.0$ and $2.5 \pm 1.9$, respectively), with lower levels of intrusive symptoms $(1.1 \pm 1.9)$ at the IES-R. $17.2 \%(N=3,558)$ reported to feel alone, $29.4 \%(N=6,080)$ to feel excluded by others and $36.9 \%(N=7,646)$ feel that "other people are around them, but not together with them", at the UCLA.
At the Brief-COPE, we found that respondents more frequently used adaptive coping strategies, such as planning (38.9\% of participants, $N=8,059)$, acceptance $(44.2 \%, N=9,156)$, and active coping $(36.2 \%, N=7,503)$. As regards maladaptive coping strategies, $10.2 \%$ $(N=2,106)$ of the sample used venting, $16 \%(N=3,321)$ self-blame and $26.2 \%(N=5,429)$ self-distraction. Moreover, a relatively high proportion of respondents $(18.4 \% ; N=3,777)$ reported to use psychoactive medications in order to cope with the situation.

At the PTGI, participants reported that they found "something positive" out of this situation, with high levels of "appreciation for life" $(51.3 \%, N=10,625)$, feeling closer to other people $(40.5 \%, N=$ $8,388)$, being more satisfied of everyday life $(42.1 \%, N=8,728)$ and increased ability to handle difficult situations $(43.9 \%, N=9,093)$. Furthermore, respondents reported a good level of resilience with a mean score of $31.3 \pm 10.4$ at the CD-RISC.

Finally, the majority of participants declared to feel supported by family $(70.6 \%, N=14,623)$ and friends $(69.8 \%, N=14,461)$, with a mean score of $21.1 \pm 6.7$ at the MSPPS family support subscale and of $20.3 \pm 6.5$ at the MSPPS friend support subscale (Table 1 ).

\section{Variations in the levels of depressive, anxiety and stress symptoms over time}

The levels of depressive symptoms increased over the period of the lockdown. In particular, depressive symptoms changed from $12.1 \pm 7.5$ in the week March 30 to April 8 to $13.1 \pm 7.4$ in the week April 30 to May $4(p<0.0001)$. Anxiety symptoms increased from $7.5 \pm 6.7$ in the week March 30 to April 8 to $8.5 \pm 7.2$ in the week April 30 to May $4(p<0.0001)$. Furthermore, the levels of stress symptoms increased from $16.0 \pm 7.2$ in the week March 30 to April 8 to $17.2 \pm 6.7$ in the week April 30 to May 4 ( $p<0.0001)$. These increases were higher in female participants compared to males (Figures 1-3; $p<0.0001$ ).

\section{Factors associated with depressive, anxiety and stress symptoms}

The multivariate regression analyses are reported in Table 3. According to the multivariate regression models, weighted for the propensity score, weeks of exposure to the pandemic and to the related containment measures were significantly associated with worsening of depressive symptoms, with Beta coefficient ranging from 0.4 (95\% Confidence Interval, CI: 0.1-0.8) during the week April 9-15 to 1.5 (95\% CI: 0.8-2.4) in the week April 30May 4. Similarly, also anxiety symptoms (from Beta: 0.4, 95\% CI: 0.1-0.7 in the week April 9-15 to Beta: 2.4, 95\% CI: 1.7-3.1 in the week April 30-May 4) and stress symptoms (Week April 30-May 4, Beta: 1.5, 95\% CI: 0.7-2.3; Week April 16-22, Beta: 0.8, 95\% CI: $0.3-1.3)$ tended to increase over time, even after controlling for the potential role of confounders, such as infection rate and mortality rate for COVID-19 in Italy.

Other factors associated with worse levels of depressive-anxiety symptoms include being affected by a pre-existing mental disorder (DASS-Depression: Beta: 3.5, 95\% CI: 2.7-4.3; DASS-Anxiety: Beta: 4.2, 95\% CI: 3.5-4.9), having been infected by the COVID19 (DASS-Depression: Beta: 1.3, 95\% CI: 0.6-1.9; DASS-Anxiety: Beta: $1.4,95 \%$ CI: $0.8-2.0$ ), and having a pre-existing physical disease (DASS-Depression: Beta: 0.9, 95\% CI: 0.6-1.1; DASSAnxiety: Beta:1.3, 95\% CI: 1.1-1.6; DASS-Stress: Beta: 0.7, 95\% CI: 0.4-0.9). Moreover, the risk of severe depressive, anxiety and stress symptoms were double in female compared to male participants $(p<0.05)$. 
Table 1. Socio-demographic and clinical characteristics of the sample $(N=20,720)$

\begin{tabular}{|c|c|}
\hline Age, years, mean $\pm S D$ & $40.4 \pm 14.3$ \\
\hline \multicolumn{2}{|l|}{ Age groups, \% (N) } \\
\hline 18-24 years old & $15.2(3,151)$ \\
\hline $25-55$ years old & $65.2(13,514)$ \\
\hline 55-64 years old & $14.0(2,904)$ \\
\hline over 65 years old & $5.6(1,151)$ \\
\hline Gender, $F, \%(N)$ & $71(14,720)$ \\
\hline Living with partner, yes, $\%(N)$ & $52.2(10,808)$ \\
\hline University degree, yes, \% $(N)$ & $62(12,844)$ \\
\hline Employed, yes, \% (N) & $70(14,518)$ \\
\hline Lost job due to the pandemic, yes, \% (N) & $6.3(1,302)$ \\
\hline Are you practicing smart working, yes, $\%(N)$ & $34.2(7,089)$ \\
\hline Spending more time on Internet, yes, \% ( $N$ ) & $80.1(16,598)$ \\
\hline Any comorbid physical condition(s), yes, \% (N) & $14.5(3,012)$ \\
\hline Any mental health problem(s), yes, \% $(N)$ & $5.5(1,133)$ \\
\hline Have you been infected by COVID-19, yes, $\%(N)$ & $1.4(296)$ \\
\hline $\begin{array}{l}\text { Have you been isolated due to COVID-19 infection, yes, \% } \\
\text { (N) }\end{array}$ & $1.5(316)$ \\
\hline $\begin{array}{l}\text { Have you been in contact with someone affected by COVID- } \\
19, \%(N)\end{array}$ & $4.2(866)$ \\
\hline \multicolumn{2}{|l|}{ Clinical characteristics } \\
\hline $\begin{array}{l}\text { General Health Questionnaire-global score, mean } \pm \text { SD } \\
\text { (range: } 0-12 \text { ) }\end{array}$ & $5.6 \pm 1.6$ \\
\hline $\begin{array}{l}\text { Obsessive compulsive inventory-global score, mean } \pm \\
\text { SD (range: } 0-72 \text { ) }\end{array}$ & $10.7 \pm 8.2$ \\
\hline Insomnia severity index, mean \pm SD (range: $0-28$ ) & $9.8 \pm 5.2$ \\
\hline $\begin{array}{l}\text { Suicidal Ideation Attributes Scale (SIDAS), mean } \pm \text { SD } \\
\text { (range: } 0-50 \text { ) }\end{array}$ & $4.9 \pm 6.6$ \\
\hline $\begin{array}{l}\text { Severity of Acute Stress Symptoms- Adult, mean } \pm \text { SD } \\
\text { (range: } 0-28 \text { ) }\end{array}$ & $6.0 \pm 4.9$ \\
\hline \multicolumn{2}{|l|}{ Impact of event scale, mean \pm SD (range: $0-5$ ) } \\
\hline Intrusion & $1.1 \pm 1.9$ \\
\hline Avoidance & $2.3 \pm 2.0$ \\
\hline Hyperarousal & $2.5 \pm 1.9$ \\
\hline Loneliness, mean \pm SD (range: $0-24$ ) & $19.1 \pm 3.6$ \\
\hline \multicolumn{2}{|l|}{ Coping strategies, mean \pm SD (range: $1-4$ ) } \\
\hline \multicolumn{2}{|l|}{ Maladaptive strategies } \\
\hline Self-distraction & $2.7 \pm 0.8$ \\
\hline Denial & $1.5 \pm 0.7$ \\
\hline Venting & $2.7 \pm 0.8$ \\
\hline Behavioral disengagement & $1.6 \pm 0.6$ \\
\hline Self-blame & $2.4 \pm 0.8$ \\
\hline Substance use & $1.2 \pm 0.5$ \\
\hline \multicolumn{2}{|l|}{ Adaptive strategies } \\
\hline Acceptance & $3.1 \pm 0.7$ \\
\hline Active & $2.9 \pm 0.8$ \\
\hline Emotional support & $2.4 \pm 0.8$ \\
\hline Use of information & $2.4 \pm 0.8$ \\
\hline
\end{tabular}

Table 1. Continued

\begin{tabular}{|c|c|}
\hline Positive reframing & $2.3 \pm 0.7$ \\
\hline Planning & $3.0 \pm 0.8$ \\
\hline \multicolumn{2}{|l|}{ Other } \\
\hline Religion & $1.9 \pm 0.9$ \\
\hline Humour & $2.1 \pm 0.8$ \\
\hline \multicolumn{2}{|l|}{ Post-traumatic growth inventory, mean \pm SD (range: $0-10$ ) } \\
\hline Personal strength & $2.1 \pm 3.4$ \\
\hline Spiritual change & $3.7 \pm 2.9$ \\
\hline Appreciation for life & $6.4 \pm 3.2$ \\
\hline Relating to others & $5.3 \pm 1.6$ \\
\hline New possibilities & $5.8 \pm 1.6$ \\
\hline $\begin{array}{l}\text { Connor-Davidson Resilience Scale, mean } \pm \text { SD (range: 0- } \\
\text { 40) }\end{array}$ & $31.3 \pm 10.4$ \\
\hline \multicolumn{2}{|l|}{$\begin{array}{l}\text { Multidimensional scale of perceived social support, } \\
\text { mean } \pm \text { SD (range: } 4-28 \text { ) }\end{array}$} \\
\hline Family support & $21.1 \pm 6.7$ \\
\hline Friends support & $20.3 \pm 6.5$ \\
\hline Support from other relevant ones & $22.3 \pm 6.7$ \\
\hline
\end{tabular}

Abbreviations: COVID-19, Coronavirus disease 2019; SD, Standard deviation.

Table 2. Levels of depression, anxiety and stress during the lockdown period.

\begin{tabular}{|c|c|c|}
\hline \multicolumn{3}{|c|}{ DASS-Depression subscale, mean \pm SD: $12.2 \pm 7.5$} \\
\hline & \multicolumn{2}{|c|}{ Global sample } \\
\hline & $\mathrm{N}$ & $\%$ \\
\hline Normal (range: 0-9) & 7,608 & 36.7 \\
\hline Mild (range: $10-12$ ) & 2,980 & 14.4 \\
\hline Moderate (range: 13-20) & 7,569 & 36.5 \\
\hline Severe (range: $21-27$ ) & 2,271 & 11.0 \\
\hline Extremely severe (range: 28-42) & 284 & 1.4 \\
\hline \multicolumn{3}{|c|}{ DASS-Anxiety subscale, mean \pm SD: $7.4 \pm 6.8$} \\
\hline & \multicolumn{2}{|c|}{ Global sample } \\
\hline & $\mathrm{N}$ & $\%$ \\
\hline Normal (range: 0-6) & 10,836 & 52.3 \\
\hline Mild (range: 7-9) & 2,773 & 13.4 \\
\hline Moderate (range: $10-14$ ) & 3,469 & 16.7 \\
\hline Severe (range: 15-19) & 2,085 & 10.1 \\
\hline Extremely severe (range: $20-42$ ) & 1,548 & 7.5 \\
\hline \multicolumn{3}{|c|}{ DASS-Stress subscale, mean \pm SD: $16.3 \pm 7.1$} \\
\hline & \multicolumn{2}{|c|}{ Global sample } \\
\hline & $\mathrm{N}$ & $\%$ \\
\hline Normal (range: $0-10$ ) & 3,877 & 18.7 \\
\hline Mild (range: 11-18) & 8,216 & 39.7 \\
\hline Moderate (range: $19-26)$ & 7,728 & 37.3 \\
\hline Severe (range: $27-34$ ) & 891 & 4.3 \\
\hline Extremely severe (range: $35-42$ ) & 0 & 0 \\
\hline
\end{tabular}

Abbreviations: DASS, Depression, Anxiety, Stress Scale; SD, Standard deviation. 


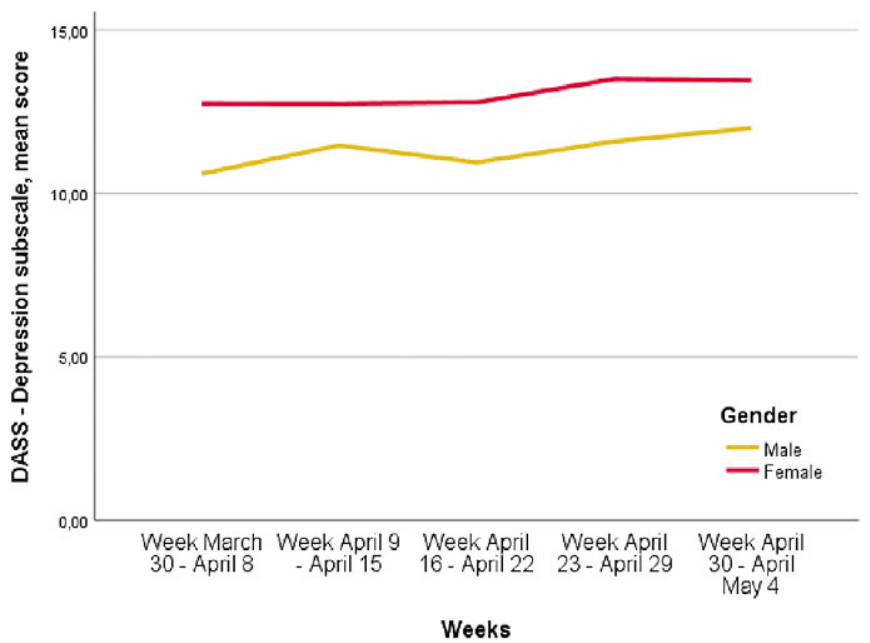

Figure 1. Depression, Anxiety, Stress Scale (DASS)-Depression mean score variation over time, $p<0.0001$ ( $p<0.0001$ refers to the differences of the different time points).

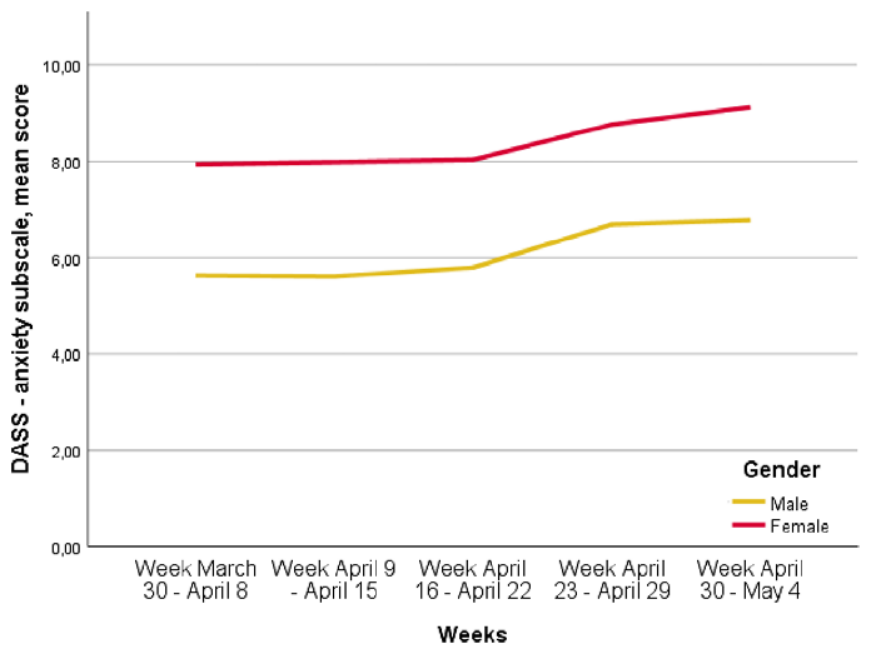

Figure 2. Trend of Depression, Anxiety, Stress Scale (DASS)-Anxiety mean scores over time in men and women ( $p<0.0001$ refers to the different time points).

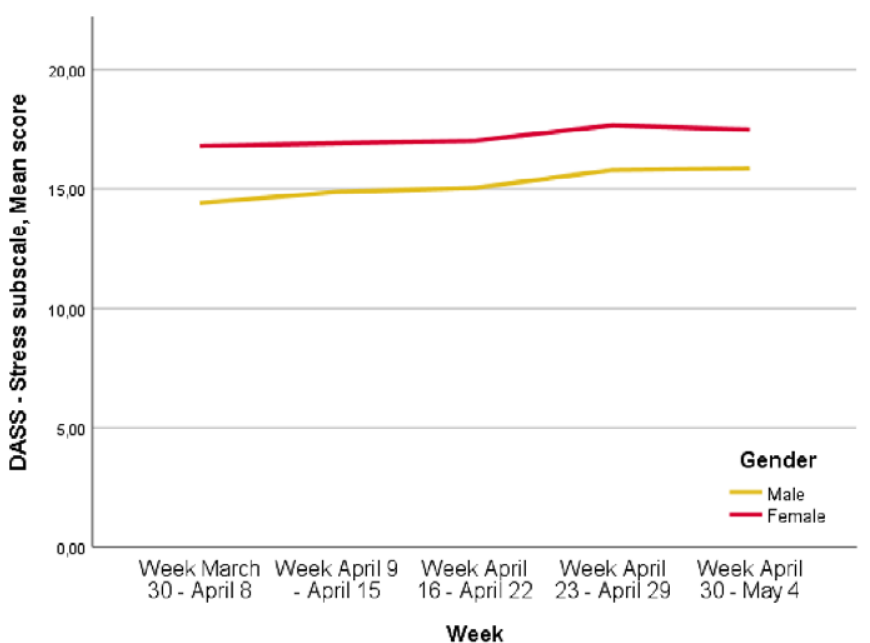

Figure 3. Depression, Anxiety, Stress Scale (DASS)-Stress mean score variation over time, $p<0.0001(p<0.0001$ refers to the differences at the different time points). 
Table 3. Regression models weighted by propensity score.

\begin{tabular}{|c|c|c|c|c|c|c|c|c|c|c|c|c|}
\hline & \multicolumn{4}{|c|}{ DASS-Depression } & \multicolumn{4}{|c|}{ DASS-Anxiety } & \multicolumn{4}{|c|}{ DASS-Stress } \\
\hline & \multirow[b]{2}{*}{$\begin{array}{l}\text { Beta } \\
\text { coefficient }\end{array}$} & \multirow[b]{2}{*}{$\begin{array}{c}p \\
\text { value }\end{array}$} & \multicolumn{2}{|c|}{$\begin{array}{c}95 \% \\
\text { Confidence } \\
\text { interval }\end{array}$} & \multirow[b]{2}{*}{$\begin{array}{c}\text { Beta } \\
\text { coefficient }\end{array}$} & \multirow[b]{2}{*}{$\begin{array}{c}p \\
\text { value }\end{array}$} & \multicolumn{2}{|c|}{$\begin{array}{c}95 \% \\
\text { Confidence } \\
\text { interval }\end{array}$} & \multirow[b]{2}{*}{$\begin{array}{c}\text { Beta } \\
\text { coefficient }\end{array}$} & \multirow[b]{2}{*}{$\begin{array}{c}p \\
\text { value }\end{array}$} & \multicolumn{2}{|c|}{$\begin{array}{c}95 \% \\
\text { Confidence } \\
\text { interval }\end{array}$} \\
\hline & & & $\begin{array}{l}\text { Lower } \\
\text { bound }\end{array}$ & $\begin{array}{l}\text { Upper } \\
\text { bound }\end{array}$ & & & $\begin{array}{l}\text { Lower } \\
\text { bound }\end{array}$ & $\begin{array}{l}\text { Upper } \\
\text { bound }\end{array}$ & & & $\begin{array}{l}\text { Lower } \\
\text { bound }\end{array}$ & $\begin{array}{l}\text { Upper } \\
\text { bound }\end{array}$ \\
\hline Intercept & 7.816 & 0.000 & 6.294 & 9.338 & 4.531 & 0.000 & 3.161 & 5.9 & 12.318 & 0.000 & 10.851 & 13.785 \\
\hline Quarantine, yes & 0.988 & 0.014 & 0.197 & 1.780 & -0.157 & 0.666 & -0.869 & 0.555 & -0.147 & 0.706 & -0.910 & 0.616 \\
\hline Having a pre-existing mental health problem & 3.475 & 0.000 & 2.670 & 4.279 & 4.224 & 0.000 & 3.500 & 4.948 & 0.449 & 0.257 & -0.327 & 1.224 \\
\hline Having been infected by COVID & 1.284 & 0.000 & 0.604 & 1.963 & 1.435 & 0.000 & 0.823 & 2.047 & 0.136 & 0.684 & -0.519 & 0.791 \\
\hline Being healthcare professional & -0.064 & 0.867 & -0.815 & 0.687 & 0.284 & 0.411 & -0.393 & 0.960 & 0.223 & 0.547 & -0.502 & 0.947 \\
\hline $\begin{array}{l}\text { Having a pre-existing physical } \\
\text { comorbid condition }\end{array}$ & 0.859 & 0.000 & 0.568 & 1.150 & 1.370 & 0.000 & 1.108 & 1.632 & 0.718 & 0.000 & 0.437 & 0.998 \\
\hline Gender female, ref. Male & 1.885 & 0.000 & 1.6 & 2.103 & 2.177 & 0.000 & 1.981 & 2.372 & 2.148 & 0.000 & 1.939 & 2.358 \\
\hline \multicolumn{13}{|l|}{ Occupational status, ref. employed } \\
\hline housewife & 1.118 & 0.000 & 0.523 & 1.713 & 1.503 & 0.000 & 0.967 & 2.038 & 0.250 & 0.393 & -0.324 & 0.823 \\
\hline unemployed & 1.233 & 0.000 & 0.866 & 1.599 & 0.624 & 0.000 & 0.294 & 0.953 & -0.709 & 0.000 & -1.062 & -0.356 \\
\hline retired & 0.872 & 0.000 & 0.617 & 1.127 & 0.327 & 0.005 & 0.098 & 0.556 & -0.415 & 0.001 & -0.660 & -0.170 \\
\hline Being in one of the most affected Italian regions & 0.264 & 0.017 & 0.048 & 0.481 & 0.460 & 0.000 & 0.265 & 0.654 & -0.092 & 0.389 & -0.300 & 0.117 \\
\hline \multicolumn{13}{|l|}{ Time to exposure, ref. week March 30 to April 8} \\
\hline Week April 15 to April 9 & 0.462 & 0.008 & 0.119 & 0.806 & 0.413 & 0.009 & 0.104 & 0.723 & 0.329 & 0.050 & 0.002 & 0.661 \\
\hline Week April 16 to April 22 & 0.792 & 0.003 & 0.274 & 1.309 & 1.022 & 0.000 & 0.557 & 1.488 & 0.835 & 0.001 & 0.336 & 1.334 \\
\hline Week April 23 to April 29 & 1.467 & 0.000 & 0.869 & 2.064 & 1.841 & 0.000 & 1.304 & 2.379 & 1.424 & 0.000 & 0.848 & 2.000 \\
\hline Week April 30 to May 4 & 1.581 & 0.000 & 0.786 & 2.377 & 2.372 & 0.000 & 1.656 & 3.088 & 1.515 & 0.000 & 0.748 & 2.282 \\
\hline Age & -0.042 & 0.000 & -0.050 & -0.034 & -0.046 & 0.000 & -0.053 & -0.039 & -0.051 & 0.000 & -0.059 & -0.043 \\
\hline Number of cohabiting people & -0.188 & 0.000 & -0.263 & -0.114 & -0.012 & 0.736 & -0.079 & 0.056 & 0.214 & 0.000 & 0.142 & 0.285 \\
\hline Global satisfaction with life & -0.430 & 0.000 & -0.479 & -0.381 & -0.228 & 0.000 & -0.272 & -0.184 & -0.198 & 0.000 & -0.246 & -0.151 \\
\hline Satisfaction with cohabiting people & -0.054 & 0.026 & -0.101 & -0.006 & -0.138 & 0.000 & -0.180 & -0.095 & 0.039 & 0.096 & -0.007 & 0.084 \\
\hline Satisfaction with housing & 0.003 & 0.901 & -0.045 & -0.051 & -0.043 & 0.051 & -0.085 & 0.000 & 0.059 & 0.012 & 0.013 & 0.104 \\
\hline GHQ-global score & 0.367 & 0.000 & 0.335 & 0.398 & 0.219 & 0.000 & 0.190 & 0.247 & 0.308 & 0.000 & 0.278 & 0.338 \\
\hline Hours spent on Internet & 0.151 & 0.000 & 0.116 & 0.186 & 0.178 & 0.000 & 0.146 & 0.210 & 0.055 & 0.002 & 0.021 & 0.089 \\
\hline Loneliness global score & 0.084 & 0.000 & 0.054 & 0.114 & 0.045 & 0.001 & 0.018 & 0.072 & 0.029 & 0.053 & 0.000 & 0.057 \\
\hline Cases of COVID in Italy & 0.001 & 0.045 & 4.96 & 0.000 & 0.001 & 0.004 & 9.0 & 0.000 & 0.000 & 0.002 & 0.000 & 0.001 \\
\hline Mortality rate of COVID in Italy & 0.001 & 0.379 & -0.001 & 0.002 & 0.002 & 0.015 & 0.000 & 0.003 & 0.000 & 0.541 & -0.002 & 0.001 \\
\hline
\end{tabular}


Protective factors against the development of psychiatric symptoms included higher levels of satisfaction with one's own life and with cohabiting people, and living with a higher number of family members $(p<0.05)$.

\section{Discussion}

The COMET is the first trial evaluating the global impact of the COVID-19 pandemic and its related containment measures on several dimensions of mental health in a large sample of the Italian population.

One of our main findings is the presence of moderate to severe levels of depressive, anxiety, and stress symptoms which are higher than those found in China [52, 68, 69]. This difference could be due to the type of immediate health response in the two countries, with clear lockdown measures from the beginning of the pandemic in China [70] and a more fragmented preventive approach in Italy, which may have increased the levels of fears and uncertainty in this country [37-39, 71]. In fact, the uncertainties about the pandemic progression, the "hypochondriac concerns" [72] and fear that the epidemic is difficult to control represent triggering factors for the development of mental health problems $[73,74]$. Moreover, studies carried out during natural disasters, war, fires and terroristic attacks found high levels of depressive/anxiety-related symptoms in the general population [75-81], but nevertheless they were significantly lower compared to those we found in our study. These data confirm that the current pandemic is an unprecedented event in terms of its impact on the mental health of the general population.

A second interesting finding of our survey is that the levels of anxiety, depressive and stress symptoms increased over time, being more severe in the last weeks of the lockdown, as also found in our regression models controlled for all socio-demographic characteristics of respondents. This finding confirms the hypothesis that the duration of containment measures significantly influences mental health and well-being of the general population, as also found by Sibley et al. [73] in a sample of the general population in New Zealand. Moreover, this trend has not been influenced by the rate of COVID cases and COVID mortality rates in Italy, highlighting that these public measures-although being necessary for infection control-should be removed as soon as possible in order to safeguard public mental health.

Female participants are at higher risk of developing depressiveanxiety symptoms, as already shown in small Italian samples [82, 83 ] and in previous outbreaks [84]. This finding can be due to the higher incidence in women of anxiety-depressive disorders [85-88] and of anxious, cyclothymic and depressive temperaments in women [37], also in community-based samples [89].

Moreover, being affected by a pre-existing mental health problem represents an independent significant risk factor for the development of depressive, anxiety and stress symptoms, as already reported by Plunkett et al. [90] and Hao et al. [14]. This finding suggests the need to provide as soon as possible adequate and tailored supportive interventions to mentally ill patients, who represent fragile and at-risk individuals that have been overlooked during the initial phases of the pandemic [91-95].

During the lockdown participants reported an increased time spent on Internet, which was associated with a higher risk of developing mental health problems, thus not confirming our hypothesis of a protective effect played by Internet on mental health. This finding may be due to the diffusion through Internet of uncontrolled and unreliable information and fake news, which may have increased the levels of anxiety and depressive symptoms in people who are alone and with lower levels of education [96]. This finding highlights the need for media professionals to receive an appropriate training, in order to provide unbiased and nonsensationalistic information during catastrophic events.

Being unemployed, retired or housewife was significantly associated with higher levels of anxiety-depressive symptoms [13]. In the UK, belonging to a socio-economic disadvantaged group increased the risk of developing mental health problems, according to a gradient across the different weeks of the lockdown [17]. This finding highlights the need for global, multi-level socio-economic initiatives aiming to reduce the negative effect of the pandemic on the society [97]. These data should also be interpreted considering the high rate (14.5\%) of suicidal ideation/suicidal thoughts found in our sample. The rate of suicidal ideation found in our sample is quite impressive, compared with the $3 \%$ found in a previous epidemiological study carried out in Italy [98]. Several factors may contribute to the increased rate of suicidal ideation in the Italian general population, including uncertainty about the future, loneliness, physical distancing, unemployment, economic recession and interpersonal violence [99]. All these risk factors should be taken into account in the implementation of actions aiming to prevent suicide [100-102].

Participants reported several disturbances in sleep quality and patterns, as already found in other studies carried out in China and in other European countries $[103,104]$. The public health containment measures implemented worldwide have markedly changed daily routines and may have had an impact on sleep pattern and on the risk of developing other mental health problems $[105,106]$. In order to develop tailored innovative preventive and/or therapeutic strategies, the specific socio-demographic and clinical predictors of sleep problems should be identified.

Finally, good levels of perceived social support and of posttraumatic growth in the aftermath of the pandemic have been reported from the Italian general population participating in our survey. It may be that the Italian socio-cultural context, with strong family ties and social relationships, may have positively impacted on the perception of mutual social support [107]. However, longitudinal studies may help to evaluate changes in the levels of posttraumatic growth, resilience, and social support in the subsequent phases of the ongoing health crisis [108].

Our study has several strengths. This is the first study carried out in different geographic Italian regions with a large sample from the general population during the lockdown period. Validated and reliable assessment instruments have been used in order to investigate several domains of mental health and psychological wellbeing according to a propensity score analysis. Moreover, as primary outcome we have selected the same assessment tool (the DASS-21) used in studies carried out in China in order to allow direct comparisons between the two countries. Although the DASS21 scores in the Italian general population prior of the pandemic are not available, the comparison of our findings with national statistics (https://www.epicentro.iss.it/mentale/epidemiologia-italia) document higher levels of anxiety, depressive and stress symptoms during the pandemic. Therefore, the increased frequency of depressive-anxiety symptoms in our sample could be interpreted as COVID-19 related, although this causal association should be further investigated. In any case, we believe that the analysis of DASS-21 over the different weeks of lockdown provide an important contribution to the field in order to clarify the direct impact of the pandemic on the mental health.

We are aware that the use of an online tool is not the best methodological choice, since it may have excluded elderly people 
or those living in socially disadvantaged contexts [109]. However, this choice was necessary in order to reach a large portion of Italian population in a short time and in a pandemic situation, when faceto-face contacts are forbidden [110].

Finally, it must be acknowledged that collected data are related to depressive or anxiety symptoms, which cannot be considered as sufficient to formulate a diagnosis of depressive/anxiety disorders. Therefore, this survey represents an initial step for the promotion of appropriate screening procedures in the general population for the early detection of full-blown mental disorders.

The present study has several clinical implications: (a) to promote mass screening campaigns for the general population in order to identify the presence of subthreshold mental disorders; (b) to disseminate informative intervention on how to deal with the mental health consequences of the pandemic; and (c) to support at-risk population-mainly people with pre-existing mental health problems and COVID-19 patients-with tailored innovative psychosocial interventions.

In conclusion, there is the need to address mental health needs as an integral part of COVID-19 response. In fact, although physical isolation and lockdown represent essential public health measures for containing the spread of the COVID-19 pandemic, they are a serious threat for mental health and well-being of the general population. It is necessary to get prepared if a next emergency will come, in order to provide appropriate community-based mental health service responses to the population.

Financial support. This research received no specific grant from any funding agency, commercial or not-for-profit sectors.

Conflicts of Interest. The authors have no conflicts of interest to disclose.

Data Availability Statement. The dataset is not available for sharing.

Ethical Standards. The authors assert that all procedures contributing to this work comply with the ethical standards of the relevant national and institutional committees on human experimentation and with the Helsinki Declaration of 1975, as revised in 2000. The Ethical Review Board of the University of Campania "L. Vanvitelli" has approved the study.

\section{References}

[1] Fiorillo A, Gorwood P. The consequences of the COVID-19 pandemic on mental health and implications for clinical practice. Eur Psychiatry. 2020; 63:e32.

[2] Chen S, Bonanno GA. Psychological adjustment during the global outbreak of COVID-19: a resilience perspective. Psychol Trauma. 2020; 12(S1):S51-4. doi: 10.1037/tra0000685.

[3] Marazziti D, Stahl SM. The relevance of COVID-19 pandemic to psychiatry. World Psychiatry. 2020;19:261.

[4] Centers for Disease Control and Prevention. Update: use of quarantine to prevent transmission of severe acute respiratory syndrome-Taiwan. MMWR Morbid Mortal Wkly Rep. 2003;52:680-3.

[5] Wasserman D, van der Gaag R, Wise J. The term "physical distancing" is recommended rather than "social distancing" during the COVID-19 pandemic for reducing feelings of rejection among people with mental health problems. Eur Psychiatry. 2020;63:e52.

[6] Onder G, Rezza G, Brusaferro S. Case-fatality rate and characteristics of patients dying in relation to COVID-19 in Italy. JAMA. 2020;323:1775, 6.

[7] Wu C, Chen X, Cai Y, Xia J, Zhou X, Xu S, et al. Risk factors associated with acute respiratory distress syndrome and death in patients with coronavirus disease 2019 pneumonia in Wuhan, China. JAMA Int Med. 2020;13: e200994
[8] Fauci AS, Lane HC. Redfeld RR Covid-19-navigating the uncharted. N Engl J Medicine. 2020;382:1268-9.

[9] Kuzman MR, Curkovic M, Wasserman D. Principles of mental health care during the COVID-19 pandemic. Eur Psychiatry. 2020;63:e45.

[10] Thome J, Coogan AN, Simon F, Fischer M, Tucha O, Faltraco F, et al. The impact of the COVID-19 outbreak on the medico-legal and human rights of psychiatric patients. Eur Psychiatry. 2020;63:e50.

[11] Horesh D, Brown AD. Traumatic stress in the age of covid-19: a call to close critical gaps and adapt to new realities. Psychol Trauma. 2020;12:331-5.

[12] Vindegaard N, Eriksen Benros M. COVID-19 pandemic and mental health consequences: systematic review of the current evidence. Brain Behav Immun. 2020;S0889-1591:30954-5.

[13] Zhang SX, Wang Y, Rauch A, Wei F. Unprecedented disruption of lives and work: health, distress and life satisfaction of working adults in China one month into the COVID-19 outbreak. Psychiatry Res. 2020;288: 112958.

[14] Hao F, Tan W, Jiang L, Zhang L, Zhao X, Zou Y, et al. Do psychiatric patients experience more psychiatric symptoms during COVID-19 pandemic and lockdown? A case-control study with service and research implications for immunopsychiatry. Brain Behav Immun. 2020;87:100-6.

[15] Pfefferbaum B, North CS. Mental health and the Covid-19 pandemic. N Engl J Medicine. 2020;383:510-2.

[16] Adhanom Ghebreyesus T. Addressing mental health needs: an integral part of COVID-19 response. World Psychiatry. 2020;19:129-30.

[17] Wright L, Steptoe A, Fancourt D. Are we all in this together? Longitudinal assessment of cumulative adversities by socioeconomic position in the first 3 weeks of lockdown in the UK. J Epidemiol Community Health. 2020;74:683-8.

[18] Gruber C. Impaired interferon signature in severe COVID-19. Nat Rev Immunol. 2020;20:353.

[19] Unützer J, Kimmel RJ, Snowden M. Psychiatry in the age of COVID-19. World Psychiatry. 2020;19:130-1.

[20] Brooks SK, Webster RK, Smith LE, Woodland L, Wessely S, Greenberg N, et al. The psychological impact of quarantine and how to reduce it: rapid review of the evidence. Lancet. 2020;395:912-20.

[21] Constantino JN. Prevention of child maltreatment: strategic targeting of a curvilinear relationship between adversity and psychiatric impairment. World Psychiatry. 2018;17:103-4.

[22] Shigemura J, Terayama T, Kurosawa M, Kobayashi Y, Toda H, Nagamine $\mathrm{M}$, et al. Mental health consequences for survivors of the 2011 Fukushima nuclear disaster: a systematic review. Part 1: psychological consequences. CNS Spectr. 2020;20:1-16.

[23] Ghodse H, Galea S. Tsunami: understanding mental health consequences and the unprecedented response. Int Rev Psychiatry. 2006;18:289-97.

[24] Perera I. Mental health and politics since the Eurozone crisis: the role of mental health professionals. Eur Psychiatry. 2019;62:28-9.

[25] Lowell A, Suarez-Jimenez B, Helpman L, Zhu X, Durosky A, Hilburn A, et al. 9/11-related PTSD among highly exposed populations: a systematic review 15 years after the attack. Psychol Med. 2018;48:537-53.

[26] Parmar D, Stavropoulou C, Ioannidis JP. Health outcomes during the 2008 financial crisis in Europe: systematic literature review. BMJ. 2016; 354:i4588.

[27] Corner E, Gill P. The nascent empirical literature on psychopathology and terrorism. World Psychiatry. 2018;17:147-8.

[28] Catani C. Mental health of children living in war zones: a risk and protection perspective. World Psychiatry. 2018;17:104-5.

[29] Shalev AY, Gevonden M, Ratanatharathorn A, Laska E, van der Mei WF, Qi W, et al. International consortium to predict PTSD. Estimating the risk of PTSD in recent trauma survivors: results of the International Consortium to Predict PTSD (ICPP). World Psychiatry. 2019;18:77-87.

[30] Campelo N, Oppetit A, Neau F, Cohen D, Bronsard G. Who are the European youths willing to engage in radicalisation? A multidisciplinary review of their psychological and social profiles. Eur Psychiatry. 2018;52: 1-14.

[31] Patel V, Burns JK, Dhingra M, Tarver L, Kohrt BA, Lund C. Income inequality and depression: a systematic review and meta-analysis of the association and a scoping review of mechanisms. World Psychiatry. 2018; 17:76-89. 
[32] Mandavilli A. SARS epidemic unmasks age-old quarantine conundrum. Nat Med. 2003;9:487.

[33] Twu SJ, Chen TJ, Chen CJ, Olsen SJ, Lee LT, Fisk T, et al. Control measures for severe acute respiratory syndrome (SARS) in Taiwan. Emerg Infect Dis. 2003;9:718-20.

[34] De Natale G, Ricciardi V, De Luca G, De Natale D, Di Meglio G, Ferragamo A, et al. The COVID-19 infection in Italy: a statistical study of an abnormally severe disease. J Clin Med. 2020;9:1564.

[35] Monforte AD, Tavelli A, Bai F, Tomasoni D, Falcinella C, Castoldi R, et al. The importance of patients' case-mix for the correct interpretation of the hospital fatality rate in COVID-19 disease. Int J Infect Dis. 2020;100:P67-74.

[36] Michelozzi P, de' Donato F, Scortichini M, De Sario M, Noccioli F, Rossi $\mathrm{P}$, et al. Mortality impacts of the coronavirus disease (COVID-19) outbreak by sex and age: rapid mortality surveillance system, Italy, 1 February to 18 April 2020. Euro Surveill. 2020;25(19):2000620.

[37] Moccia L, Janiri D, Pepe M, Dattoli L, Molinaro M, De Martin V, et al. Affective temperament, attachment style, and the psychological impact of the COVID-19 outbreak: an early report on the Italian general population. Brain Behav Imm. 2020;S0889-1591:30586-9.

[38] Sani G, Janiri D, Di Nicola M, Janiri L, Ferretti S, Chieffo D. Mental health during and after the COVID-19 emergency in Italy. Psychiatry Clin Neurosci. 2020;74(6):372.

[39] Cerami C, Santi GC, Galandra C, Dodich A, Cappa SF, Vecchi T, et al. COVID-19 outbreak in Italy: are we ready for the psychosocial and the economic crisis? Baseline findings from the psycovid study. Front Psychiatry. 2020;11:556.

[40] Giallonardo V, Sampogna G, Del Vecchio V, Luciano M, Albert U, Carmassi $\mathrm{C}$, et al. The Impact of quarantine and physical distancing following COVID-19 on mental health: study protocol of a multicentric italian population trial. Front Psychiatry. 2020;11:533.

[41] Singla DR, Raviola G, Patel V. Scaling up psychological treatments for common mental disorders: a call to action. World Psychiatry. 2018;17:226-7.

[42] Linardon J, Cuijpers P, Carlbring P, Messer M, Fuller-Tyszkiewicz M. The efficacy of app-supported smartphone interventions for mental health problems: a meta-analysis of randomized controlled trials. World Psychiatry. 2019;18:325-36.

[43] Aboujaoude E. Telemental health: why the revolution has not arrived. World Psychiatry. 2018;17:277-8.

[44] Wasil AR, Weisz JR, DeRubeis RJ. Three questions to consider before developing a mental health app. World Psychiatry. 2020;19:252-3.

[45] Torous J, Firth J. Bridging the dichotomy of actual versus aspirational digital health. World Psychiatry. 2018;17:108-9.

[46] Firth J, Torous J, Stubbs B, Firth JA, Steiner GZ, Smith L, et al. The "online brain": how the Internet may be changing our cognition. World Psychiatry. 2019;18:119-29.

[47] Torous J, Andersson G, Bertagnoli A, Christensen H, Cuijpers P, Firth J, et al. Towards a consensus around standards for smartphone apps and digital mental health. World Psychiatry. 2019;18:97-8.

[48] Bucci S, Lewis S, Ainsworth J, Haddock G, Machin M, Berry K, et al. Digital interventions in severe mental health problems: lessons from the Actissist development and trial. World Psychiatry. 2018;17:230-1.

[49] Lovibond SH, Lovibond PF. Manual for the depression anxiety \& stress scales. 2nd ed. Sydney: Psychology Foundation, 1995.

[50] Ho CS, Chee CY, Ho RC. Mental health strategies to combat the psychological impact of COVID-19 beyond paranoia and panic. Ann Acad Med Singapore. 2020;49:1-3.

[51] McAlonan GM, Lee AM, Cheung V, Cheung C, Tsang KW, Sham PC, et al. Immediate and sustained psychological impact of an emerging infectious disease outbreak on health care workers. Can J Psychiatry. 2007;52:241-7.

[52] Wang C, Pan R, Wan X, Tan Y, Xu L, Ho CS, et al. Immediate psychological responses and associated factors during the initial stage of the 2019 Coronavirus Disease (COVID-19) epidemic among the general population in China. Int J Environ Res Public Health. 2020;17:1729.

[53] Goldberg DP, Gater R, Sartorius N, Ustun TB, Piccinelli M, Gureje O, et al. The validity of two versions of the GHQ in the WHO study of mental illness in general health care. Psychol Med. 1997;27:191-7.
[54] Foa EB, Huppert JD, Leiberg S, Langner R, Kichic R, Hajcak G, et al. The obsessive-compulsive inventory: development and validation of a short version. Psychol Assess. 2002;14:485-96.

[55] Morin CM, Belleville G, Bélanger L, Ivers H. The insomnia severity index: psychometric indicators to detect insomnia cases and evaluate treatment response. Sleep. 2011;34:601-8.

[56] van Spijker BA, Batterham PJ, Calear AL, Farrer L, Christensen $\mathrm{H}$, Reynolds J, et al. The suicidal ideation attributes scale (SIDAS): community-based validation study of a new scale for the measurement of suicidal ideation. Suicide Life Threat Behav. 2014;44:408-19.

[57] American Psychiatric Association. Severity of acute stress symptomsadult (National Stressful Events Survey Acute Stress Disorder Short Scale [NSESSS]), 2013.

[58] Thoresen S, Tambs K, Hussain A, Heir T, Johansen VA, Bisson JI. Brief measure of posttraumatic stress reactions: impact of event scale-6. Soc Psychiatry Psychiatr Epidemiol. 2010;45:405-12.

[59] Hays RD, Di Matteo MR. A short-form measure of loneliness. J Pers Assess. 1987;51:69-81.

[60] Carver CS. You want to measure coping but your protocol' too long: consider the brief cope. Int J Behav Med. 1997;4:92-100.

[61] Cann A, Calhoun LG, Tedeschi RG, Taku K, Vishnevsky T, Triplett KN, et al. A short form of the posttraumatic growth inventory. Anxiety Stress Coping. 2010;23:127-37.

[62] Connor KM, Davidson JRT. Development of a new resilience scale: the Connor-Davidson Resilience Scale (CD-RISC). Depress Anxiety. 2003 18:71-82.

[63] Zimet GD, Dahlem NW, Zimet SG, Farley GK. The multidimensional scale of perceived social support. J Personal Assess. 1988;1:30-41.

[64] Maslach C, Jackson SE. MBI: Maslach Burnout Inventory. Palo Alto, CA: Consulting Psychologists Press, 1981.

[65] Haukoos JS, Lewis RJ. The propensity score. JAMA. 2015;314:1637-8.

[66] Raad H, Cornelius V, Chan S, Williamson E, Cro S. An evaluation of inverse probability weighting using the propensity score for baseline covariate adjustment in smaller population randomised controlled trials with a continuous outcome. BMC Med Res Methodol. 2020;20:70.

[67] Rubin DB. Multiple imputation for nonresponse in surveys. New York: Wiley, 1977.

[68] Huang Y, Zhao N. Mental health burden for the public affected by the COVID-19 outbreak in China: who will be the high-risk group? Psychol Health Med. 2020;14:1-12.

[69] Li J, Yang Z, Qiu H, Wang Y, Jian L, Ji J, et al. Anxiety and depression among general population in China at the peak of the COVID-19 epidemic. World Psychiatry. 2020;19:249-50.

[70] Xiang YT, Ng CH, Yu X, Wang G. Rethinking progress and challenges of mental health care in China. World Psychiatry. 2018;17:231-2.

[71] Mazza C, Ricci E, Biondi S, Colasanti M, Ferracuti S, Napoli C, et al. A nationwide survey of psychological distress among Italian people during the COVID-19 pandemic: immediate psychological responses and associated factors. Int J Environ Res Public Health. 2020;17:3165.

[72] Furer P, Walker JR, Chartier MJ, Stein MB. Hypochondriacal concerns and somatization in panic disorder. Depression Anxiety. 1997;6:78-85.

[73] Sibley CG, Greaves LM, Satherley N, Wilson MS, Overall NC, Lee CHJ, et al. Effects of the COVID-19 pandemic and nationwide lockdown on trust, attitudes toward government, and well-being. Am Psychol. 2020; 75:618-30.

[74] Hossain MM, Sultana A, Purohit N. Mental health outcomes of quarantine and isolation for infection prevention: a systematic umbrella review of the global evidence. Epidemiol Health. 2020;42:e2020038.

[75] Norris FH, Friedman MJ, Watson PJ. 60,000 disaster victims speak: Part II. Summary and implications of the disaster mental health research. Psychiatry. 2002;65:240-60.

[76] Bonanno GA, Brewin CR, Kaniasty K, La Greca AM. Weighing the costs of disaster: consequences, risks, and resilience in individuals, families, and communities. Psychol Sci Public Interest. 2010;11:1-49.

[77] Kan S, Hongxia F, Jianming J, Wendong L, Zhaoli S, Jing G, et al. The risk perceptions of SARS and sociopsychological behaviors of urban people in China. Acta Psychol Sin. 2003;35:546-54. 
[78] Yu HYR, Ho SC, So KFE, Lo YL. The psychological burden experienced by Hong Kong midlife women during the SARS epidemic. Stress Health. 2005;21:177-84.

[79] Chua SE, Cheung V, McAlonan GM, Cheung C, Wong JW, Cheung EP, et al. Stress and psychological impact on SARS patients during the outbreak. Can J Psychiatry. 2004;49:385-90.

[80] Moser DA, Glaus J, Frangou S, Schechter DS. Years of life lost due to the psychosocial consequences of COVID-19 mitigation strategies based on Swiss data. Eur Psychiatry. 2020;63:e58.

[81] Wang S, Zhang Y, Ding W, Meng Y, Hu H, Liu Z, et al. Psychological distress and sleep problems when people are under interpersonal isolation during an epidemic: a nationwide multicenter cross-sectional study. Eur Psychiatry. 2020;28(63):e77.

[82] Somma A, Gialdi G, Krueger RF, Markon KE, Frau C, Lovallo S, et al. Dysfunctional personality features, non-scientifically supported causal beliefs, and emotional problems during the first month of the COVID-19 pandemic in Italy. Pers Individ Dif. 2020;165:110139.

[83] Alonzi S, La Torre A, Silverstein MW. The psychological impact of preexisting mental and physical health conditions during the COVID19 pandemic. Psychol Trauma. 2020;12:S236-8.

[84] Gao W, Ping S, Liu X. Gender differences in depression, anxiety, and stress among college students: a longitudinal study from China. J Affect Disord. 2020;263:292-300.

[85] McLean CP, Asnaani A, Litz BT, Hofmann SG. Gender differences in anxiety disorders: prevalence, course of illness, comorbidity and burden of illness. J Psychiatr Res. 2011;45:1027-35.

[86] Schuch JJ, Roest AM, Nolen WA, Penninx BW, de Jonge P. Gender differences in major depressive disorder: results from the Netherlands study of depression and anxiety. J Affect Disord. 2014;156:156-63.

[87] Steel Z, Marnane C, Iranpour C, Chey T, Jackson JW, et al. The global prevalence of common mental disorders: a systematic review and metaanalysis 1980-2013. Int J Epidemiol. 2014;43:476-93.

[88] Gao J, Zheng P, Jia Y, Chen H, Mao Y, Chen S, et al. Mental health problems and social media exposure during COVID-19 outbreak. PLoS One. 2020;15:e0231924.

[89] de Girolamo G, Polidori G, Morosini P, Scarpino V, Reda V, Serra G, et al. Prevalence of common mental disorders in Italy: results from the European Study of the Epidemiology of Mental Disorders (ESEMeD). Soc Psychiatry Psychiatr Epidemiol. 2006;41:853-61.

[90] Plunkett R, Costello S, McGovern M, McDonald C, Hallahan B. Impact of the COVID-19 pandemic on patients with pre-existing anxiety disorders attending secondary care. Ir J Psychol Med. 2020;8:1-9.

[91] Goldman ML, Druss BG, Horvitz-Lennon M, Norquist GS, Kroeger Ptakowski K, Brinkley A, et al. Mental health policy in the era of COVID-19. Psychiatr Serv. 2020;10. doi: 10.1176/appi.ps.202000219.

[92] Kaufman K, Petkova E, Bhui K, Schulze T. A global needs assessment in times of a global crisis: world psychiatry response to the COVID-19 pandemic. BJPsychiatry Open. 2020;6:E48.
[93] Greenberg N, Brooks SK, Wessely S, Tracy DK. How might the NHS protect the mental health of health-care workers after the COVID-19 crisis? Lancet Psychiatry. 2020;7. doi: S2215-0366(20)30224-8.

[94] Hanna F, Barbui C, Dua T, Lora A, van Regteren Altena M, Saxena S. Global mental health: how are we doing? World Psychiatry. 2018;17:367-8.

[95] Jorm AF, Kitchener BA, Reavley NJ. Mental health first aid training: lessons learned from the global spread of a community education program. World Psychiatry. 2019;18:142-3.

[96] Rovetta A, Bhagavathula AS. COVID-19-related web search behaviors and infodemic attitudes in Italy: infodemiological study. JMIR Public Health Surveillance. 2020;6:e19374.

[97] Ormel J, Cuijpers P, Jorm AF, Schoevers R. Prevention of depression will only succeed when it is structurally embedded and targets big determinants. World Psychiatry. 2019;18:111-2.

[98] Scocco P, de Girolamo G, Vilagut G, Alonso J. Prevalence of suicide ideation, plans, and attempts and related risk factors in Italy: results from the European Study on the epidemiology of mental disorders--world mental health study. Compr Psychiatry. 2008;49:13-21.

[99] Alegria M, Shrout PE, Canino G, Alvarez K, Wang Y, Bird H, et al. The effect of minority status and social context on the development of depression and anxiety: a longitudinal study of Puerto Rican descent youth. World Psychiatry. 2019;18:298-307.

[100] Cutler D. How will COVID-19 affect the health care economy? JAMA. 2020;323:2237-8.

[101] McIntyre RS, Lee Y. Preventing suicide in the context of the COVID-19 pandemic. World Psychiatry. 2020;19:250-1.

[102] Berrouiguet S, Courtet P, Larsen ME, Walter M, Vaiva G. Suicide prevention: towards integrative, innovative and individualized brief contact interventions. European Psychiatry. 2018;47:25-6.

[103] Morin CM, Carrier J. The acute effects of the COVID-19 pandemic on insomnia and psychological symptoms. Sleep Med. 2020;5.

[104] Mandelkorn U, Genzer S, Choshen-Hillel S, Reiter J, Meira E, Cruz M, et al. Escalation of sleep disturbances amid the COVID-19 pandemic: a crosssectional international study. J Clin Sleep Med. 2020; doi: 10.5664/jcsm.8800.

105. Krystal AD, Prather AA, Ashbrook LH. The assessment and management of insomnia: an update. World Psychiatry. 2019;18:337-52.

[106] Irwin MR, Piber D. Insomnia and inflammation: a two hit model of depression risk and prevention. World Psychiatry. 2018;17:359-61.

[107] Luciano M, Sampogna G, del Vecchio V, Giacco D, Mulè A, de Rosa C, et al. The family in Italy: cultural changes and implications for treatment. Int Rev Psychiatry. 2012;24:149-56.

[108] Yehuda R, Lehrner A. Intergenerational transmission of trauma effects: putative role of epigenetic mechanisms. World Psychiatry. 2018;17:243-57.

[109] Baltar F, Brunet I. Social research 2.0: virtual snowball sampling method using Facebook. Internet Research. 2012;22:57-74.

[110] Pierce M, McManus S, Jessop C, John A, Hotopf M, Ford T, et al. Says who? The significance of sampling in mental health surveys during COVID-19. Lancet Psychiatry. 2020;7:567-8. 